\title{
Introduction: Whose North America? Identities, Agency, and Belonging
}

At first glance North American Studies seems a somewhat new or unknown field of scholarship in Finland. However, the North American Studies program at the University of Helsinki is already a quarter of a century old and a well-established part of the Faculty of Arts. During these 25 years the program has mainly been developed and led by the McDonnell-Douglas Chair of American Studies, Professor Emeritus Markku Henriksson. After his retirement, Rani-Henrik Andersson held the position for two years, and now the program continues under the leadership of Professor Mikko Saikku. Focusing on both Canada and the United States, the program has turned a little-known field in Finland into a great success. It sets out to combine the study of the two countries "into a single coherent interdiscipline." Yet, our goal is not just to be interdisciplinary, to use methods from various disciplines, but to fuse those methods into something new, a true cross-discipline. This program allows students to focus on Canada and the United States from the start of their university life to receiving their Master's or even Doctoral degrees in North American Studies as part of a larger Cultural Studies program.

A very visible and significant part of the program has been the biennial Maple Leaf and Eagle Conference for North American Studies. From a very modest start 30 years ago, it has developed into a highly successful, multi-day academic conference. For the North American Studies program the conference is a vital international meeting place, where representatives of the many fields within North American Studies get to come together for networking and to share ideas and represent their research. It is a vastly important venue for young Finnish scholars, who get to meet a very international crowd of high profile scholars. The Maple Leaf and Eagle has 
become a unique forum where especially those studying Indigenous people and minorities have found fruitful cooperation. Speakers from around the world represent fields such as history, literature, media studies, and cultural studies, as well as other fields in humanities and social sciences. Over the years, our presenters have also included artists, whose work nicely compliments the more traditional academic research.

The title of the 2016 conference was "Whose North America? Identities, Agency, and Belonging." The purpose of the theme was to ignite discussion on the multicultural character of North America, as well as on the role of various minorities as part of American and Canadian cultures, history, and present day. The theme of the conference tied with many contemporary topics. 1) The already complex race relations in the United States seemed to be going from bad to worse, and continue to do so in the Trump era. 2) Legal and illegal immigration especially in the United States was a major topic in the presidential elections, and continues to be in the limelight. 3) Climate change and the resulting new exploitation of natural resources have had a great impact especially in northern parts of the continent, and on the lives of Canadian and Alaskan native people. 4) The fight for LGBTQ-rights gained a significant milestone when marriage laws finally caught up with general tide of progressing attitudes, but this hardly subdued the public discussion on the issue. Many of these themes were also brought to the forefront by our keynote speakers, Professors Greg Robinson, Edgar Barrens, and Phillip J. Deloria.

The 2016 meeting represented an exciting venue where traditional North American Studies themes met with current and global topics. One of the strengths of the Maple Leaf and Eagle Conference, in general, is its ability to cross borders. Critical international discussion that has taken place outside the United States has also opened new horizons to American and Canadian researchers.

Since the conference was such a success, we were extremely delighted by the opportunity to present some of the papers in American Studies in Scandinavia. We want to thank former journal editor Ari Helo for his support and current editor Janne Lahti for continuing to work with us on this special journal issue Whose North America? Identities, Agency, and Belonging.

It is, of course, understandable that we cannot publish all of the more than 80 papers that were presented during the conference. So, we decided to have an open call for all participants. We received a considerable number 
of proposals. The selection process was conducted by the current editorial team aided by the entire conference committee. The process was not easy, since the proposals were of very high quality. After the initial selection, the authors were asked to send full texts for a review by the editorial team. The authors then revised their texts accordingly and those texts were then sent to outside reviewers, who gave their insightful comments. The editorial team wishes to thank our readers for their valuable input and time.

We had several criteria in the selection process. First and foremost, we wanted the journal articles to reflect the many topics within the conference themes, and we wanted to include texts by scholars of different levels of seniority. And, somehow, the articles had to work together as a coherent journal. For these reasons, the selected manuscripts range from a very reflective text by Professor William Chafe, "History Matters," to more contemporary and empirical ones by, for example, Professor Dominique Cadinot, "Becoming Part of Mainstream America or Asserting a New Muslim-Americanness: How American Muslims Negotiate their Identity in a post 9/11 Environment." Other articles deal with Native Americans and the environment, ambiguities of African American racial representation, the contested nature of citizenship, the drawing of borders and policies, landownership and identity politics, and Southern codes of honor.

In May 2018, the Maple Leaf and Eagle Conference for North American Studies will again take place in Helsinki. This year the conference theme is "Ideas, Ideals, and Ideologies" that shape North America and the study of North America. Like the themes of our previous conference, this year's topics will surely prove equally timely and exciting. It seems that the debate on what America is, to whom it belongs, and the ideas and ideals it is created upon, is more important than ever. With the publication of these eight articles in American Studies in Scandinavia, we hope to contribute to this ongoing debate and we wish to challenge the 2018 conference participants to engage in and take this discourse into new directions.

\section{Guest Editors}

Rani-Henrik Andersson (2016 Conference Director)

Saara Kekki

Juho Turpeinen

Janne Salminen 